\title{
Influence of the Substrate Bias Voltage on the Crystallographic Structure and Surface Composition of Ti6A14V Thin Films Deposited by rf Magnetron Sputtering
}

\author{
J. E. Alfonso*, J. Torres*, and J. F. Marco ${ }^{\dagger}$ \\ * Physics of Condensed Matter Group, Physics Department, \\ Universidad Nacional de Colombia, A.A. 14490, Bogotá D.C, Colombia. and \\ $\dagger$ †nstituto de Química-Física "Rocasolano”, CSIC, c/ Serrano, 119. 28006 Madrid, Spain
}

Received on 8 December, 2005

\begin{abstract}
In this work, the influence of the substrate bias on the crystalline structure and surface composition of Ti6Al4V thin films prepared by rf magnetron sputtering were studied. Samples were grown onto two different types of substrates: AISI 420 steel and common glass using a Ti6Al4V (99.9 \%) target. Substrate bias was varied from $-100 \mathrm{~V}$ to $-200 \mathrm{~V}$. Samples were characterized by X-ray diffraction (XRD), Energy Dispersive X-ray Analysis (EDX), Scanning Electron Microscopy (SEM), and X-Ray Photoelectron Spectroscopy (XPS). It was observed that the increase of the substrate voltage improved the crystallinity of the deposited films. The stoichiometry of the deposited thin films was studied by EDX and found to be slightly different from that of the target material. Finally, the passive film spontaneously formed on the deposited films upon exposure to the laboratory atmosphere was studied by XPS. The composition of the passive film is rather complex since it contains several forms of oxidized titanium and vanadium as well as $\mathrm{Al}_{2} \mathrm{O}_{3}$.
\end{abstract}

Keywords: Sputtering; Bias; Steel

\section{INTRODUCTION}

It is well known that the physical and mechanical properties of pure titanium are improved when the material is alloyed with aluminum and vanadium at specific concentrations. Specifically, the alloy composed by $90 \%$ of titanium, $6 \%$ of aluminum and $4 \%$ of vanadium (Ti-6Al-4V) (Titanium grade 5) has emerged as one of the highest performance alloys among the different grades of Titanium. Due to its mechanical properties (high wear resistance, hardness, tenacity and resistance to fatigue and corrosion) it has arisen as an alternative structural material in the aeronautic industry. Furthermore, Ti6A14V has shown excellent bio-compatibility allowing its inclusion as metallic bio-medical implant, together with steels and super-alloys [1].

Titanium and their alloys can be deposited by two techniques: Chemical Vapor Deposition (CVD) and Physical Vapor Deposition (PVD). However, some problems are generated when carbon steel substrates are used under the CVD technique, mainly because those substrates lose its carbon because of the high substrate temperature used during the deposition process. Therefore, the most used technique to deposit the Titanium grade 5 thin films is PVD (Physical Vapor Deposition) in its variations: rf-dc sputtering $[2,3]$ and flash evaporation [4]. Magnetron sputtering is a low temperature substrate process, which has the advantage that the application of a substrate bias voltage can promote structure refinement through re-sputtering effects. The thickness of the films obtained by PVD can vary between 0.5 and $15 \mu \mathrm{m}$. These films have been used to improve the mechanical properties of steels employed in cutting tools and to coat materials used in the aerospace industry or to improve adherence (as interface) between another film and a substrate [5].This work presents the results obtained from the deposition of Ti6A14V thin films by rf magnetron sputtering on glass substrates and on AISI 420 steel and the influence that the application of a voltage bias to the substrate has on the cristallinity, stoichiometry, and surface composition of the deposited films.

\section{EXPERIMENTAL DETAILS}

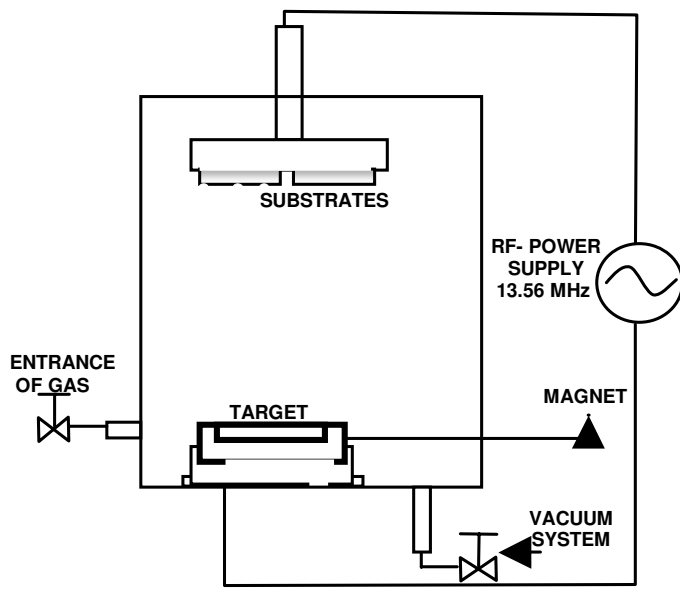

FIG. 1: System used in the deposition of the Ti6Al4V thin films.

The equipment used to grow the Ti6A14V thin films is a HS 2000 Alcatel. It consists of an rf magnetron and a vacuum system comprising a vacuum chamber and vacuum pumps (mechanical and turbo-molecular), a gas mixer and gas flux and final pressure controls (Fig. 1).

The films were obtained from a Ti6A14V target 4 inches in diameter that was bombarded with argon (99.99\%) ions. The deposition parameters were: Power $500 \mathrm{~W}$, total pressure $0.3 \mathrm{~Pa}$, Ar flux $8 \mathrm{sccm}$, target-substrate distance $5 \mathrm{~cm}$ and deposition time $30 \mathrm{~min}$. The substrate bias voltage was taken as study parameter and varied between -100 to - 
$200 \mathrm{~V}$. The structural characterization of the films was carried out by XRD, with a Shimatsu 6000 diffractometer using $\mathrm{Cu} \mathrm{K} \alpha$ radiation. The morphology and composition of the thin films were examined with a SEM Phillips microscope equipped with EDX. The composition of the passive film spontaneously formed on the deposited alloys was studied by XPS. XPS spectra were recorded with a triple channeltron CLAM2 analyser using $\mathrm{Al} \mathrm{K} \alpha$ radiation and a constant analyser transmission energy of $20 \mathrm{eV}$. Base pressure in the analyser chamber during the XPS experiments was typically around $6.67 \times 10^{-7} \mathrm{~Pa}$. All binding energy (BE) values were charge-corrected to the adventitious $\mathrm{C}$ 1s signal $(284.6 \mathrm{eV})$. The BE's values are accurate to $\pm 0.2 \mathrm{eV}$. Atomic ratios were calculated using tabulated atomic sensitivity factors.

\section{RESULTS AND DISCUSSION}

The XRD pattern recorded from the Ti6A14V films deposited on steel and glass substrates are presented in fig. 2 (a) and 2 (b), respectively, as a function of the substrate bias voltage. The films grown on steel at $-100 \mathrm{~V}$ showed, in addition to the diffraction peaks of the substrate material (note that in all the diffractograms recorded from the films deposited onto steel diffraction peaks from the substrate are still visible) a quite broad peak which corresponds to the (002) the plane of the $\alpha$-phase of Ti. The diffractograms corresponding to the films deposited at $-120 \mathrm{~V}$ present two well defined peaks at $35.1^{0}(100)$ and $38.4^{0}(110)$ which we associate with the $(\alpha / \beta)$-alloy phase. The film deposited at a bias voltage of $160 \mathrm{~V}$ shows a peak at 38.4 which can be associated to (110) plane of the $\beta$ - phase of Ti. When the bias voltage increases up to $-200 \mathrm{~V}$ the diffractogram shows only one high intensity peak at $38.4^{0}(110)$, which can be associated to the $\beta$ - phase of Ti. It is also observed that the width of the diffraction peaks is narrower for the films deposited at higher bias voltages, especially for that deposited at $-200 \mathrm{~V}$, what suggests that increasing the bias voltage increases the grain size of the deposited films. The films grown on glass at $120 \mathrm{~V}$ and $-200 \mathrm{~V}$, present a similar behavior, although there are two differences: the two peaks appearing in the diffractogram of the film grown at $120 \mathrm{~V}$ show a different intensity ratio than those of the film grown on steel and the diffractogram of the film grown at $200 \mathrm{~V}$ shows an additional low-intensity peak at $82.3^{\circ}$ which we associate with the (220) reflection of the Ti $\beta$ - phase.

In summary, it follows from the XRD data that the substrate bias voltage (hereinafter $\mathrm{V}_{b}$ ) has a large influence on the structure of the deposited films: the increase of the bias voltage promotes the growth of different phases of titanium having well-defined different preferential crystallographic orientations. The increase of $\mathrm{V}_{b}$ is also reflected in a better crystallinity of the deposited films. The data also show that the crystalline phases formed at different $\mathrm{V}_{b}$ are the same in both substrates.

This behaviour can be explained by the growth mechanisms involved in the thin film deposition process using the rf magnetron technique. The technique generates the ionization of the species present in the plasma formed during the deposi- tion; this ionization favours the growth of materials with composition and structure similar to those of the target. Moreover, when a bias voltage is applied ( $\mathrm{Vb}$ ) to the substrate, thermodynamic processes are fostered which allow the improvement of adherence between film and substrate, favoring the formation of films with good crystallinity and preferred crystallographic orientations [6]. These processes increase the kinetic energy of the species being deposited, through a mechanism known as re-sputtering, that increases both the adaptom mobility during deposition and substrate temperature (Ts).

(a)

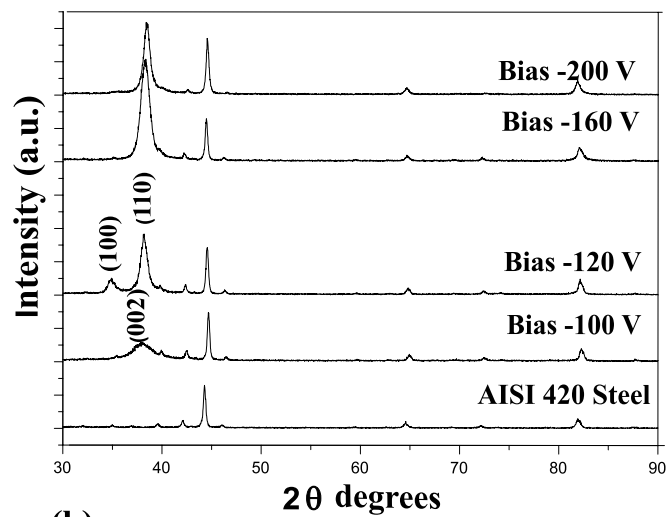

(b)

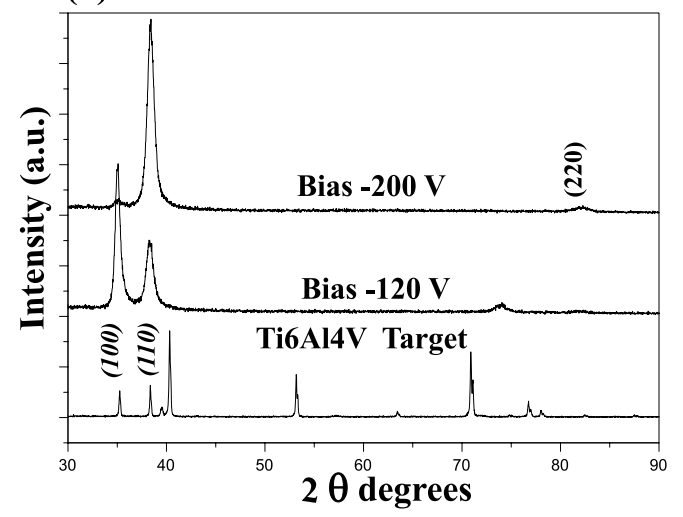

FIG. 2: (a). XRD pattern of the Ti6A14V films deposited by $\mathrm{rf}$ magnetron on steel substrates. The substrate appears as reference. (b) XRD pattern of the films growth on glass and spectrum of the Ti6A14V in bulk.

Both increasing $\mathrm{V}_{b}$ and Ts results in the elimination of voids and, consequently, in an increase of the density of the film. This has been recently shown to occur during the deposition and growth of TiN films [6].

The EDX analysis of the films showed that the stoichiometry of the deposited films departed slightly from the stoichiometry of the target material. For example, for the samples grown at $-200 \mathrm{~V}$, the EDX analysis gave values such as 87 at. \% Ti, 9 at. $\% \mathrm{Al}$ and 4 at. $\% \mathrm{~V}$. A similar composition was observed in samples grown at $120 \mathrm{~V}: 86$ at. $\% \mathrm{Ti}, 10$ at. $\% \mathrm{Al}$ and 4 at. $\%$ $\mathrm{V}$, while the EDX analysis of the material in bulk rendered a composition of 84 . at \% of Ti, 13 at. $\%$ of $\mathrm{Al}$ and 3 at. $\%$ of $\mathrm{V}$. Although, in principle, it should be expected that a increase in $\mathrm{V}_{b}$ would be reflected in a stoichiometry of the films closer to 

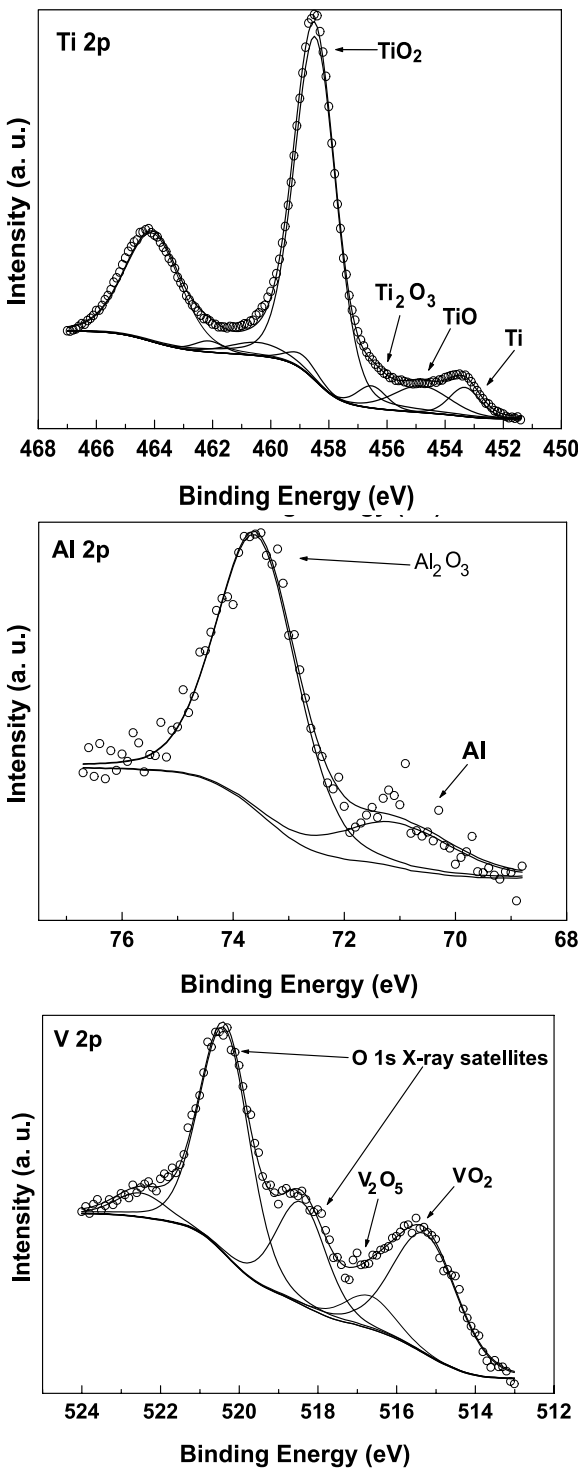

FIG. 3: Ti $2 p, A l 2 p$ and V 2p XPS narrow-scan spectra recorded from a film deposited at a bias voltage of $-120 \mathrm{~V}$.

that of the target material [6], it could be possible that, under the used experimental conditions, the sputtering rates of $\mathrm{Ti}$, $\mathrm{Al}$ and $\mathrm{V}$ from the target were slightly different giving place to the mentioned difference in stoichiometry.

The spontaneously passive film formed on the deposited films upon exposure to the air was studied by XPS. In general, the differences observed among the different films were very small and cannot be considered significant. Figure 3 shows high-resolution narrow-scan spectra recorded from the Ti $2 \mathrm{p}$, $\mathrm{V} 2 \mathrm{p}$ and $\mathrm{Al} 2 \mathrm{p}$ spectra recorded from one of the samples. All the narrow-scan spectra recorded from the rest of the samples are almost identical to those presented in Fig. 3.

The Ti $2 p$ spectrum shows several contributions and is similar to that reported previously by other authors for the spontaneously formed passive oxide layer on bulk Ti6Al4V alloy [7]. The spectrum is dominated by a major $\mathrm{TiO}_{2}$ contribution $(\mathrm{BE}$ Ti $2 \mathrm{p}_{3 / 2}=458.4 \mathrm{eV}, 82 \%$ ) and shows smaller metallic Ti (BE $\left.\mathrm{Ti} 2 \mathrm{p}_{3 / 2}=453.3 \mathrm{eV}, 5 \%\right)$, TiO (BE Ti $\left.2 \mathrm{p}_{3 / 2}=454.8 \mathrm{eV}, 9 \%\right)$ and $\mathrm{Ti}_{2} \mathrm{O}_{3}\left(\mathrm{BE} \mathrm{Ti} 2 \mathrm{p}_{3 / 2}=456.5 \mathrm{eV}, 4 \%\right.$ ) contributions. The Al $2 \mathrm{p}$ spectrum shows a major $\mathrm{Al}_{2} \mathrm{O}_{3}$ contribution at $73.6 \mathrm{eV}$ and a minor $\mathrm{Al}^{0}$ contribution at $71.0 \mathrm{eV}$. Again this spectrum is similar to that observed for the passive oxide layer formed on Ti6Al4V alloy [7]. The fit of the V 2p spectrum is complicated by the fact that the $\mathrm{V}$ peaks overlap strongly with the $\mathrm{O}$ $1 \mathrm{~s} \mathrm{~K} \alpha_{3,4} \mathrm{X}$-ray satellite peaks. Therefore, the whole spectrum was fitted considering the presence of these satellites and the presence of vanadium peaks. The results show the presence of an intense peak at $515.4 \mathrm{eV}$ which we associate to the presence of $\mathrm{VO}_{2}$ [7] and a less intense vanadium contribution at $516.7 \mathrm{eV}$ which corresponds to $\mathrm{V}_{2} \mathrm{O}_{5}$ [7]. This finding contrast with those of Milosev et al [7] who did not find oxidized vanadium in the passive layer formed on bulk Ti6Al4V. The O 1s spectrum (not shown) shows three different contributions: a main one at $530.2 \mathrm{eV}$ that can be associated to metal-oxygen bonds and two much less intense contributions at $531.7 \mathrm{eV}$ and $532.8 \mathrm{eV}$ which can correspond to the presence of $\mathrm{OH}^{-}$ groups and chemisorbed water, respectively.

\section{CONCLUSION}

The results obtained in this work, under the stated experimental conditions, clearly showed that the increase of the bias voltage promotes the growth of different phases of titanium having well-defined different preferential crystallographic orientations. The increase of $\mathrm{V}_{b}$ is also reflected in a better crystallinity of the deposited films. The data also showed that the crystalline phases formed at different $\mathrm{V}_{b}$ are the same in both substrates. The composition of the passive film formed on the deposits is rather complex since it contains several forms of oxidized titanium and vanadium as well as $\mathrm{Al}_{2} \mathrm{O}_{3}$.
[1] S. Roessler, R. Zimmermann, D. Scharnweber, C. Werner, and H. Worch. Colloids and Surfaces B. Biointerfaces 26, 387 (2002).

[2] J. Musil, Surf. Coat. Technol. 125, 322 (2000).

[3] S. Veprek and M. Jilek, Pure Appl. Chem. 74, 38, 475 (2002).

[4] W. Herr,E. Broszeit, Surf. Coat. Technol, 97, 335 (1997).

[5] P. H. Myhofer and C. Mitteder, Surf. Coat. Technol. 133, 131
(2000).

[6] P. Patsalas, C. Charitidis, and S. Logothetidis, Surf. Coat. Technol. 125, 335 (2000).

[7] I. Milosev, M. Metikos-Hukovic, and H.-H Strehblow, Biomaterials 21, 2103 (2000). 